HIBRIDISMO Y MULATOCRACIA: BIOPOLÍTICA, RAZA Y MESTIZAJE EN LA OBRA DE FERNANDO GONZÁLEZ

\title{
HIBRIDISMO Y MULATOCRACIA: BIOPOLÍTICA, RAZA Y MESTIZAJE EN LA OBRA DE FERNANDO GONZÁLEZ1
}

\author{
Julián Harruch Morales \\ Universidad de los Andes (Colombia) \\ jharruchm@gmail.com
}

Recibido: 15/02/2020 - Aprobado: 15/04/2020

DOI: doi.org/10.17533/udea.lyl.n78a19

\begin{abstract}
Resumen: Este artículo examina desde una perspectiva biopolítica la teorización del mestizaje latinoamericano del intelectual colombiano Fernando González Ochoa. Se analizan las propuestas de mestizaje eugenésico y de construcción de una democracia racial(izada) con las cuales González intervino en los debates que tuvieron lugar en Colombia, durante las primeras décadas del siglo XX, en torno al progreso social de la nación y su «problema racial». El artículo busca así contribuir a la cartografía de los presupuestos y contradicciones articuladores de la ideología racista y eurocéntrica compartida por un amplio sector de la intelectualidad colombiana (y latinoamericana) del periodo histórico señalado.
\end{abstract}

Palabras clave: Fernando González; biopolítica; raza; mestizaje; eugenesia.

\section{HYBRIDISM AND MULATTOCRACY: BIOPOLITICS, RACE, AND MESTIZAJE IN FERNANDO GONZÁLEZ'S WORK}

\begin{abstract}
This article examines, from a biopolitical perspective, Colombian intellectual Fernando Gonzalez's theorization of Latin American mestizaje. It centers on the proposals for a eugenic hybridization and the construction of a racial(ized) democracy through which González partook in the debates held in Colombia, during the first decades of the twentieth century, on the nation's social progress and its «racial problem». The article seeks to contribute, in this way, to the cartography of the presuppositions and contradictions underpinning the racist and eurocentric ideology of a wide sector of Colombian (and Latin American) intellectuals of the aforementioned historical period.
\end{abstract}

Key words: Fernando González; biopolitics; race; hybridity; eugenics.

1. El artículo que se presenta es una versión abreviada de la investigación con la que el autor optó al título de Magíster en Literatura de la Universidad de los Andes (Colombia), la cual lleva el mismo título y fue dirigida por el profesor David Solodkow. 


\section{Introducción}

$\mathrm{E}$ ste artículo se ocupa de las ideas sobre la raza y el mestizaje del intelectual colombiano Fernando González Ochoa (1895-1964). La presente aproximación se articula alrededor de dos ejes: su propuesta de mestizaje eugenésico para formar una nueva raza gran colombiana, la raza del «Gran Mulato», a partir del cruce de los distintos «tipos humanos» habitantes del continente americano: negros, blancos e indígenas; y su propuesta para la construcción de un cierto tipo de democracia racial(izada), la «mulatocracia». El argumento central radica en que las ideas de González sobre el mestizaje ilustran una concepción del «problema racial» latinoamericano - la cual contó con diferentes formulaciones en el discurso de muchos intelectuales de la época- que se asienta en lo que se denominará hibridismo: la idea de que, debido a un proceso de mestizaje inconcluso, ${ }^{2}$ los latinoamericanos constituyen un tipo humano híbrido, en contraste con seres y grupos humanos racialmente (i.e., biológica y culturalmente) formados. La teorización gonzaliana del mestizaje, como se mostrará, descansa en la idea de que el pueblo colombiano posee una naturaleza híbrida que comportaría deficiencias físicas, intelectuales, morales, etc. que impedirían el progreso social y cultural de la nación y que, por tanto, harían necesaria una intervención eugenésica del Estado.

A través del análisis propuesto, este artículo busca aportar elementos para una cartografía ideológica de los debates en torno a lo racial y lo social que tuvieron lugar entre los intelectuales colombianos durante las primeras décadas del siglo XX y, más específicamente, en los años de la República Liberal (1930-1946) —durante la cual se concentró la mayor parte de la producción escrita de González, justamente aquella en que la reflexión política es más intensa y constante-. Durante ese periodo, en el cual Colombia atravesó un proceso de (incipiente) industrialización y, en general, de afianzamiento del modelo de producción capitalista, los debates de la intelectualidad hegemónica colombiana en torno a lo social y lo racial estuvieron estrechamente vinculados entre sí, puesto que para

2. Mestizaje inconcluso es un concepto acuñado por Solodkow (2020) que refiere a una concepción negativa del mestizaje latinoamericano —extraída del corpus ensayístico del intelectual colombiano Luis López de Mesa - según la cual este es «el resultado de las malas y aún no terminadas mezclas históricas, algo que debía modificarse desde una intervención biopolítica y eugenésica del Estado mediante el reemplazo y mejoramiento de la población y la incorporación de inmigración europea selectiva» (p. 12). 
muchos intelectuales de la época —incluido González-el mayor obstáculo para el progreso social y cultural de la nación residía, precisamente, en la constitución racial de la población.

La cuestión racial, en consecuencia, era inseparable de los debates en torno a cómo administrar la vida de la población a fin de introducirla en la modernidad y organizarla en función de las lógicas de la economía capitalista mundial. De ahí que la biopolítica, como perspectiva de análisis teórico, sea clave para este trabajo. Conviene, entonces, explicar, al menos muy brevemente, lo que se entiende por un análisis biopolítico.

Con esta noción Foucault (2000) caracterizaba un conjunto de técnicas y dispositivos de saber-poder, que tienen por objeto la gestión de la vida de la población con vistas a la regularización de sus procesos biológicos de conjunto, como son la reproducción y la natalidad, la morbilidad y la mortalidad, la vejez y la invalidez, entre otros fenómenos que, abstraídos de su ocurrencia en casos individuales, exhiben efectos y constantes en el nivel colectivo y a lo largo de periodos de tiempo más o menos largos. Se trata, dice Foucault, de un tipo de racionalidad gubernamental que busca incrementar la productividad económica de la población y asegurar su sujeción política (pp. 222-225) ${ }^{3}$. El análisis biopolítico que se intentó realizar en este texto, así pues, refiere al examen de las ideas relacionadas con el gobierno de la vida de la población que se encuentran en la obra de González, es decir, con sus diagnósticos y propuestas atinentes al mantenimiento, control y mejora del «organismo social» $\mathrm{y}$ — tema biopolítico por excelencia del ensayo latinoamericano de los siglos XIX y $\mathrm{XX}$ - a su constitución como nación: hay que tener en cuenta que González entendía su función social y pedagógico-cultural como intelectual, fundamentalmente, como la de creador de los relatos fundacionales que aglutinarían a una nueva nación grancolombiana; un propósito que asoma tesoneramente, de una forma $\mathrm{u}$ otra, en todos sus libros, bien por medio de la crítica cultural y literaria, de la observación sociológica y el cuadro de costumbres, o de la indagación histórica, la confesión, la especulación metafísica, o de la

3. Como lo recordó Virno (2013): «El cuerpo viviente se convierte en objeto a ser gobernado no por su valor intrínseco, sino porque es el sustrato de lo que realmente importa: la fuerza de trabajo como el agregado de las más diversas facultades humanas» (p. 271; traducción propia). Y como agrega Díaz (2008), «Para el modo de producción capitalista es necesario un modo de vida capitalista» (p. 43). Son dos objetivos, así pues, que están en directa correspondencia: a mayor utilidad de la población, mayor es también su docilidad, y viceversa. 
sátira de la vida social y de los personajes públicos, y aún tras el relato novelado y el ensayo moral, psicológico o estético ${ }^{4}$.

Puede considerarse que es relativamente poca la atención que se le ha prestado en el ámbito académico al pensamiento político de González, en general, y a sus ideas raciales, en particular. ${ }^{5}$ A lo cual se suma que entre los estudios que existen muchos se ocupan del pensamiento de González de una forma muy exegética y abstracta. Con esto puede decirse que se limitan a explicar conceptos y relaciones entre conceptos, sin atender suficientemente a la relación que la obra gonzaliana guarda con debates políticos concretos de su época. En cuanto al tema de la raza y el mestizaje, puntualmente, hay una tendencia entre los intérpretes de la obra de González a centrarse en su impugnación de la tesis de que la «mezcla racial» es por sí misma negativa, así como en el complejo de inferioridad, o «complejo del hijo de puta», por medio del cual González explicaba el sometimiento no solo político y económico, sino fundamentalmente ideológico y cultural de las sociedades latinoamericanas a Europa y Estados Unidos (González, 2016, pp. 36 y 41-42). Partiendo de allí, varios análisis han exaltado la búsqueda de González de una identidad latinoamericana «auténtica», su celebración del mestizaje y su reivindicación de la raza indígena, e interpretan su narrativa racial como un proyecto visionario, inclusivo y emancipatorio, e incluso como pluriétnico y multicultural.

Por ejemplo, Marquínez (2007) resaltó la valoración positiva del mestizaje iberoamericano que habría en la obra de González, rasgo que compartiría, en su opinión, con la narrativa racial del mexicano Vasconcelos (p. 97). Rivera (2016) también realzó la que considera una orgullosa aceptación del ser híbrido del suramericano por parte de González y sostuvo que su política racial «se halla en las antípodas de la totalitaria pureza de las razas» (pp. 112 y 117). Pachón (2015), en el mismo sentido, encontró en el reconocimiento de la diversidad y de la diferencia cultural y étnica el rasgo esencial del

4. Véase al respecto, por ejemplo, González (2013, p. 471).

5. Sobre el tema son de interés algunos capítulos dentro de la biografía hecha por Henao Hidrón (1987), el libro de Pinto (1995), así como otros trabajos más de Escobar (1997), Marquínez (2007), Jiménez (2009), Aponte (2010), Aguirre (2013), Pachón (2015), Giraldo Ramírez (2016), Murcia (2016) y Rivera (2016). Por último, específicamente sobre la cuestión racial en González, se encuentra una tesis de maestría de Buitrago (2015). También hay que añadir el libro de Giraldo (2012) sobre el ensayo colombiano de interpretación del ser nacional y continental en el siglo XX, en el que el autor le dedica varias páginas a González y destaca el lugar central que en su pensamiento juega el concepto de raza (pp. 96-124). 
proyecto grancolombiano de González (pp. 170-171), y destacó que, «como José Vasconcelos, González creyó en la potencialidad de la raza [¿?], en especial, de la india» (p. 172). Buitrago (2015), por su parte, coincidió con Pachón en señalar la reivindicación de la «raza india» que habría en la obra de González, ya que esta exhibiría «un discurso eugenésico, que [...] valora el aporte racial del aborigen y no esencializa los aportes de la raza blanca como fuerza integradora para mejorar la raza» (pp. 88-89). Henao (1988), aunque advirtió de su pesimismo frente al presente racial latinoamericano, enfatizó también en que González «vislumbró la enorme potencialidad de esta raza» (p. 155) y que «su esperanza en Suramérica [...] es debida al indio. A su malicia, su reserva, la concentración dentro de sí mismo y la comunidad con las fuerzas elementales» (p. 164).

Para González, efectivamente, la «mezcla racial» era promisoria para el progreso social de la nación, de Latinoamérica y, de hecho, de la humanidad entera. Entendido como hibridación racial (física) y también cultural e ideológica, el mestizaje habría de conducir a la aparición de un nuevo tipo humano, un superhombre poseedor de «conciencia universal», el «Gran Mulato»; así como a la construcción de una sociedad humana unificada, fraterna y verdaderamente democrática, un sistema político que puede ser denominada como la «mulatocracia», en el que no habría más relaciones de dominación entre pueblos ni entre hombres. Sin embargo, por otra parte, González asoció consistentemente el mestizaje a fallas y deficiencias de carácter fisiológico, psicológico, cognitivo y, en general, a toda clase de males sociales y políticos. Además, en su narrativa, el valor positivo de la «mezcla racial» queda siempre diferido al futuro y sujeto a la acción eugenésica del Estado. El de González es un proyecto de nación que se basa, fundamentalmente, en la corrección del hibridismo biológico y cultural de la población, y que está articulado a una utopía que, en cuanto tal, solo admite la mismidad, lo puro y lo idéntico a sí mismo. ${ }^{6}$ En suma, como se mostrará, la de González es una propuesta que vio en la homogeneización del cuerpo social una condición necesaria para la consolidación y el funcionamiento del Estado nacional.

6. Solo Aponte (2010), entre los intérpretes de González revisados para este estudio, advirtió el ideal de homogeneización y mismidad que yace tras el proyecto de unificación racial y cultural para producir la raza del «Gran Mulato». 
Las tensiones delineadas merecen ser revisitadas. El propósito no es rechazar o validar las ideas políticas y raciales de González, finalidades que se consideran igual de anacrónicas y de poco provecho intelectual. Lo que hace su estudio interesante hoy es que pone en evidencia con mucha claridad algunos presupuestos de la ideología racial eurocéntrica de la intelectualidad colombiana hegemónica de su tiempo. Como se demostrará, la teorización del mestizaje que elabora González hace de dicha ideología su blanco, pero termina reproduciendo su misma lógica binaria, teleológica, totalizante y excluyente.

\section{Análisis de los conceptos de hibridación, mulatocracia, biopolítica, raza y mestizaje en la obra de Fernando González}

En las primeras décadas del siglo XX, los debates que ocuparon a la clase política e intelectualidad de la época, como señala Arias (2011), estuvieron menos relacionados con las disputas ideológicas que habían dado lugar durante el siglo XIX a las guerras civiles entre liberales y conservadores, tales como la organización administrativa del Estado (centralismo vs. federalismo) o la relación entre este y la Iglesia Católica, y más con los problemas sociales creados o recrudecidos como consecuencia del auge económico y el proceso de industrialización que estaba atravesando el país, el cual dio lugar a numerosos conflictos sociales en el campo, donde se agudizaron los enfrentamientos entre campesinos y latifundistas por la propiedad de la tierra, y, en las ciudades - las cuales vieron entonces un rápido crecimiento demográfico-, entre el proletariado en formación y los patronos, sometidos como estaban los primeros a muy precarias condiciones laborales, sanitarias, educativas y de vivienda (pp. 30-32). En este contexto, las exigencias que imponía la modernización del país, los conflictos y el descontento social que se aparejaron con ese proceso, como sostuvo Solodkow (2019), «tuvieron como corolario el que la población se volviera un objeto de intervención para la política estatal (salubridad pública, educación popular, control de la natalidad, transporte, alimentación, entre otros) y un objeto de debate en los discursos de los intelectuales» (p. 51). 
Más allá de las diferencias específicas que pudieran tener sobre estos temas, sobre lo que no había mayor disenso entre intelectuales y políticos de los dos partidos tradicionales era respecto al «atraso» material, social y cultural en el que estaría abismado el país. La «raza» filtraba en todas esas discusiones. Para muchos de ellos, como ha sido ampliamente estudiado, ${ }^{7}$ el atraso de la nación obedecía a las características raciales de la población, a su ser producto de una «mezcla» entre «elementos humanos muy dispares» y que incluía a «razas inferiores»: indígenas y negros. Se trata de una imagen-del-mundo estructurada por, y estructurante de, el patrón de poder basado en la clasificación social eurocéntrica de la población mundial, que tiene su origen en la época moderna/colonial. Como subrayó Quijano (2000), la distinción entre razas primitivas y civilizadas, que a su vez se corresponde con la diferenciación entre sociedades tradicionales y modernas, precapitalistas y capitalistas, etc., fue entonces $-\mathrm{y}$ siguió siendo- esencial en el mecanismo de legitimación de las relaciones sociales de dominación, en la medida en que situaba en una natural condición de inferioridad no solo las características físicas, sino también las formas de organización social y los descubrimientos culturales y epistemológicos de las sociedades no europeas (pp. 203 y 209).

Debido a la preponderancia de los discursos y saberes de la biología —el movimiento eugenésico, el evolucionismo spenceriano, el darwinismo social—, en auge a comienzos del siglo XX, dicha concepción cristalizó entre los intelectuales colombianos en una comprensión de la raza como el agregado de las características diferenciadoras de un «pueblo», las cuales estarían inscritas en su código genético y serían transmitidas hereditariamente. Entre estas se contaban no solo los rasgos fenotípicos (como el color de la piel), sino cualidades morales, espirituales, emocionales e intelectuales. El campo semántico del concepto, por tanto, no se circunscribía a lo biológico, aunque allí tuviera su suelo discursivo. O mejor, el dominio de lo biológico comprendía y se extendía también a lo emotivo y lo psicológico, e incluso hasta lo sociopolítico.

7. Acerca del debate sobre la raza entre la intelectualidad colombiana de los años 20, se puede consultar, entre otros, los trabajos de Pedraza (1997), Castro-Gómez (2007), Solodkow (2020), Díaz (2008) y Arias (2011). 
Para quienes mantenían una lectura biologicista de los predicamentos de la nación, el remedio a la degeneración racial de la población, si lo había, residía en una redirección eugenésica del proceso de mestizaje que permitiera reparar los daños ocasionados por esa mezcolanza aleatoria y a la deriva que habría tenido lugar en el continente. Desde esta perspectiva, se precisaba modificar las proporciones de la mezcla racial, ahogando los elementos «primitivos»y «bárbaros» en grandes cantidades de sangre perteneciente a «tipos humanos superiores». Este tipo de propuestas que veían en la dirección «científica» y «eugenésica» del mestizaje un alivio para los supuestos padecimientos raciales de la nación, a pesar de que no llegaron a implementarse, no fueron escasas entre los contemporáneos de González y provinieron tanto de conservadores como de liberales, de un Laureano Gómez lo mismo que de un Luis López de Mesa, ${ }^{8}$ por ejemplo, aunque no de todos ellos.

En la obra de González, el tema del atraso de la nación aparecería bajo la forma de una petición de principio: la idea de que no existía algo como la cultura colombiana o americana. En su opinión, las sociedades del continente no habían hecho ninguna contribución al acumulado de la cultura universal (González, 2016, p. 32). Esa negación rotunda de la actividad cultural de los pueblos latinoamericanos es el punto de partida de su ideación política. De ahí que, sostenía González, la misión del Estado debía ser fundamentalmente cultural: crear y desarrollar la cultura americana (2016, p. 48). A lo largo de su obra de madurez, si bien de forma asistemática y dispersa — pues entre otras cosas González no tenía vocación de estadista-, aparecen las líneas directrices de una estrategia biopolítica que habría de conducir al advenimiento de una nueva raza suramericana, la raza del «Gran Mulato», y con ella, de una nueva humanidad ${ }^{9}$.

González articuló una concepción teleológica de la historia en la que Suramérica -y más exactamente los países de la Gran Colombia - estaba llamada a ser el escenario para

8. Véase Gómez (1970, p. 48) y López de Mesa (1970, pp. 122-123).

9. Hay que apuntar que, en los escritos de González, estas propuestas están apenas esbozadas de forma muy general, sin el detalle que se encuentra en los planes biopolíticos de otros intelectuales de la época, como por ejemplo en la del antes mencionado Luis López de Mesa. Esto se debe probablemente a que González no ocupó cargos decisivos dentro del Estado en los que tuviera a cargo la formulación de políticas públicas de largo y amplio alcance. Por tal razón, mi exposición no puede más que indicar los contornos generales de dichas propuestas. 
que la humanidad conquistara la etapa final de su evolución. Igual que en la teoría de la «raza cósmica» de Vasconcelos, ${ }^{10}$ cuya obra sin duda González conocía, la redención humana tendría lugar en estas tierras, y ello precisamente por su «originalidad física y humana»:

[...] climas variados a causa de las montañas; presiones atmosféricas variadísimas; terrenos propios para todo cultivo; aguas las más abundantes $y$ precisamente las cantidades de instintos, pasiones, etc., de todas las razas humanas necesarias para producir un tipo nuevo de cultura. Esto puede ser, indudablemente, el lugar de la renovación del hombre (González, 2016, pp. 3536).

América emerge entonces en la narrativa de González como el fin al que tiende la historia universal, y ello precisamente gracias a la fusión de todas las razas que tendría lugar en ella, dando lugar a una cultura no solo nueva, sino definitiva. Es una visión que rechaza directamente los dos tropos que sostenían la explicación biologicista del atraso latinoamericano que aparecen con frecuencia en los discursos de otros intelectuales y políticos de la época, ${ }^{11}$ a saber: que la «mezcla racial» era causa de degeneración física, social, política, etc. y que las condiciones geográficas del trópico eran desfavorables para el establecimiento y avance de la cultura y la civilización. Para González, a la inversa, son justamente las circunstancias geográficas y raciales de América las que harían de ella un escenario promisorio y ventajoso para el adelanto de la humanidad. González, de hecho, identificó explícitamente aquellas dos ideas como el núcleo del aparataje ideológico con el que se había mantenido, después de la colonia, el sometimiento de los países suramericanos $^{12}$.

Con dichas ideas, decía González, se habría perpetuado y aumentado el complejo de ilegitimidad que caracterizaría a las sociedades latinoamericanas. Por esta razón, en su opinión, los suramericanos, comenzando por sus líderes políticos e intelectuales, tenían que sobreponerse a ese trauma colonial, que hacía de ellos, según decía con estridencia, unos perfectos hijos de puta, es decir, gentes avergonzadas de lo propio - como se avergüenza, es la idea, el hijo de una mujer que se dedica al trabajo sexual- (Gonźalez, 2016, p. 32).

10. Véase Vasconcelos, (1966, p. 27).

11. El ejemplo de Laureano Gómez es de nuevo muy ilustrativo. Véase Gómez (1970).

12. Véase González (2016, p. 36). 
En resumen, no habría cultura americana mientras las sociedades de Suramérica no se reconciliasen con el hecho de ser pueblos «negroides» (e «indigenoides»; pueblos mezclados, en fin), un motivo que se puede rastrear en muchos de los ensayistas latinoamericanos desde Bolívar y pasando por Martí: la necesidad de aceptar sin vergüenza el hecho de ser los «hijos de la chingada», como lo pusiera Octavio Paz.

La autoexpresión cultural americana reclamaba, así pues, impugnar la ideología racial colonial. González pretendió mostrar que, por el contrario, la mezcla suramericana era de hecho un bien. Sin embargo, el suyo siguió siendo un discurso biológico-determinista. Las causas de la inexistencia de la cultura americana no eran en su opinión únicamente políticas e ideológicas, y por ello no bastaban medidas sociales y culturales para forjarla. Cabe añadir que González afirmó en varias ocasiones estar abordando el tema desde un punto de vista biológico ${ }^{13}$. Tal era para él en última instancia la naturaleza del problema: el origen de nuestros males se hallaría en el «hibridismo» ${ }^{14}$ de la población, y este exigía un remedio acorde, a saber, una corrección biopolítica eugenésica. Así que, en últimas, lo mismo que para López de Mesa o Laureano Gómez, salir del «atraso» implicaba para González una modificación de la condición racial local.

González no consideraba, a diferencia aquellos y de lo que se ha encontrado en muchos otros discursos biologicistas de la época, que las herencias genéticas del indígena y del negro constituyeran una tara o una anomalía. Lo que sí pensaba era que la mezcla racial latinoamericana era un proceso aún inconcluso: «Suramérica es una raza en gestación» (González, 2016, p. 74); un «laboratorio» como el del doctor Moreau, un «horno» en el que se estarían fundiendo las razas para producir un nuevo tipo humano: el «hombre adaptado y

13. Véase González (2016, pp. 24, 34, 60 y 73).

14. Se extrajo este concepto del mecanoscrito del que habría sido el segundo volumen de Mi Simón Bolívar, el cual lleva el subtítulo de El libertador. Este proyecto, como se sabe, quedó inconcluso. El mecanoscrito cuenta con 32 páginas que permanecen inéditas. Para efectos de este estudio, fue cedido con toda generosidad por la Corporación Otraparte, que lo conserva en su archivo. Allí dice González: «Mujeres, pueblos, historia y humanidad futura, perdonad a los ardientes mulatos de Suramérica la falta de realización, pues ella proviene de falta de irrigación meníngea por el hibridismo» (p. 4). De hecho, la palabra original era hibridación, pero fue tachada y reemplazada con bolígrafo por hibridismo. La misma corrección aparece más adelante: «la razón de esta deficiencia realista no está únicamente en errores científicos que aún viven en nuestra atmósfera social, sino en lo biológico, en los tejidos especializados; la causa está en el hibridismo producto de irrigación meníngea» (p. 8). Hasta donde se conoce, el término no vuelve a aparecer en ningún lugar de la obra publicada de González, aunque sí se usa constantemente el término híbrido para referirse a la condición racial de los latinoamericanos. 
armonioso»(González, 2015a, pp. 36-37). Desde esta perspectiva los suramericanos no seríamos todavía un grupo humano racialmente formado, sino híbridos, unos animales apenas parecidos al hombre. Con todo y el énfasis que González pone en la cultura, lo cierto es que la consecuencia de su teoría es que la anhelada autoexpresión americana estaría imposibilitada por la condición híbrida de la población: «Mientras no haya tipo definido, mientras seamos mulatos, la acción humana será hija de puta, con lo cual significo que será falsa» (González, 2016, p. 75).

Como se puede ver, la teoría racial de González se articula alrededor de una oposición entre lo racial y lo mestizo (híbrido), entendiendo por esto último no el producto final de una combinación racial, sino lo que está aún en proceso de mezcla. Esta conceptualización, evidentemente, contiene la problemática presuposición de que hay grupos humanos puros (no mezclados) y no puros, es decir, en proceso de mezcla. Y también que los conjuntos humanos mezclados en el subcontinente (españoles, negros e indígenas), eran bloques homogéneos; ambas ficciones racistas muy extendidas entre la intelectualidad de la época.

A esa oposición inicial, por otra parte, se acopla una serie de otras oposiciones: lo racional frente a lo sensual, lo humano frente a lo animal, lo sano frente lo enfermo y lo bello frente a lo feo ${ }^{15}$. Esta concepción aparece ya en Mi Simón Bolívar:

Observemos los cinco países independizados por Simón Bolívar. Están poblados por gentes variadísimas: negros, mulatos, mestizos, zambos... Un teatro, una reunión cualquiera, una iglesia, una escuela, son aquí como una colcha de retazos. No hay tipo determinado. Y son enfermizos como todo híbrido. Muy sensuales. El uso prematuro y el abuso de la sensualidad nos determina esta multitud de hombres torcidos y sin propósitos. Llega la excitación y la arrojan ahí mismo en gritos, en palabras, en piedras... No hay control. Falta aún el hombre. (González, 2015a, p. 35; énfasis agregados).

En este caso, la condición híbrida del suramericano está asociada a lo largo de la obra de González a toda clase de secuelas: alcoholismo, obesidad, calvicie, falta de estabilidad fisiológica, desequilibrio nervioso, perturbación meníngea, carencia de irrigación de la sangre al cerebro - y en general de los fluidos_-, sensualismo, fealdad, desarmonía en las facciones, alma triste y atormentada, conciencia de pecado, melancolía, impudicia, sexualidad prematura, estilo escritural ampuloso, rimbombante y afectado; bullosidad,

15. Otros pasajes ilustrativos de estas oposiciones se encuentran en González (2015a, p. 34; 2016, p. 74). 488 
charlatanería, turbulencia social, caos, latrocinio, vicio, inmoralidad, libertinaje, infidelidad, mendacidad, incontinencia, engaño, presunción, malicia, astucia, etc.... En suma, afirmaba González, invocando las leyes de Mendel, todo ser híbrido tiende a descomponerse y es un ser enfermizo. Y, sobre todo, es inapto para hacer, lo que González llamaba un «vicioso solitario», es decir, alguien que descarga su energía ante imaginaciones y no ante la vida. De ahí que el suramericano no fuera apto para crear y manifestar una cultura propia y que fuera irremediablemente vanidoso y simulador ${ }^{16}$.

En último término, todas las oposiciones a las que se ha hecho refererencia se engloban en una sola, aquella entre lo variado, lo múltiple y lo diverso, por una parte, y lo uno, lo homogéneo y lo mismo, por otra. Mientras lo híbrido es una «colcha de retazos», lo racialmente formado es lo semejante: «las razas perfectas son inocentes, o sea naturales, imágenes de la esencia igual a sí misma»(Gonźalez, 2015a, p. 40; énfasis agregado). La diferencia racial y cultural del pueblo, entonces, aparece como un disvalor:

En una reunión de franceses, todos son formas semejantes; por consiguiente, la reunión tiene un espíritu; son hombres de un pueblo ya biológicamente perfecto, entendiendo por esta palabra el hecho de que los instintos formaron su casa; todos los franceses se parecen, tienen su ritmo; son cuerpos en donde las almas acabaron ya de manifestarse. No tienen porvenir, pero son estéticos. Lo mismo en Inglaterra, Italia, Alemania, poco más o menos. Visitemos ahora un Congreso suramericano: ¡Qué desarmonía en las facciones! ¡Qué variedad de ensayos, qué contradictorios instintos bregan por manifestarse ahí, torciendo las narices, contrayendo frentes que no se sabe qué forma van a tener en definitiva! Dice el biólogo: Aquí, mil demonios pretenden expresarse en estos cuerpos; mil instintos asoman a estos ojos (González, 2016, p. 74; énfasis agregados).

Es interesante ver cómo funciona aquí la distinción entre «razas en gestación»y «razas perfectas o biológicamente formadas». En ella opera la misma lógica del chiste aquel de que «mi novia nunca llega tarde porque si llega tarde ya no es mi novia». Para González, por definición, no habría razas mestizas, pues si un grupo humano mestizo conforma una raza es porque ya no es mestizo. Solo lo no mezclado, o bien lo ya completamente mezclado, es una raza, no lo que se está mezclando; y únicamente lo que es «raza» es digno de valor actual, es «estético». Al fundirse unas con otras, como en América, es la idea, las razas originarias habrían perdido su estabilidad biológica y cultural, la cual solo volverían a tener cuando la mezcla adquiriera consistencia, es decir, cuando lo múltiple se hiciera

16. Véase también: González (2016, p. 78; 2015, p. 77; 2013, pp. 37, 43 y 97; 1970, p. 69).

489 
nuevamente homogéneo. Parte del mito es, por cierto, que lo que se está mezclando eventualmente se terminará de mezclar. Solo entonces, sigue el razonamiento, un pueblo tiene una individualidad racial colectiva que expresar y puede hacer un aporte «auténtico» al haber común de la humanidad ${ }^{17}$.

Cuando tal fusión sucediera en América, además, ella representaría la síntesis física, ideológica y espiritual, por fin, de «todas las razas», y ahí residía justamente su rotunda relevancia para los destinos humanos. La diferencia racial y cultural de Suramérica es entonces conceptualizada como su más grave predicamento y al tiempo como su mayor promesa: «Su único valor es el de elemento para la mezcla» (González, 2016, pp. 74-75). La síntesis racial que González imagina es eso: una síntesis. No hay espacio para distintos y variados mestizajes. La raza del Gran Mulato aparece como una nueva totalidad homogénea y universal de la que lo híbrido constituye su contrario. Este es el eje central de otras teorizaciones del hibridaje latinoamericano de la época, que se encuentra también, y especialmente, como muestra con precisión Joshua Lund (2006), en La raza cósmica, de Vasconcelos, probablemente el intelectual del continente de comienzos del siglo XX en cuya obra más comúnmente se ha querido ver una celebración del mestizaje - y una reivindicación de lo indio--

La teoría de la raza cósmica de Vasconcelos nunca fue acerca de múltiples hibridaciones, en plural, sino de una hibridación universal, en singular; no la raza como una heterogeneidad articulada de razas y culturas, sino mi raza como una sola raza homogénea; no se trata en absoluto de una hibridación sostenible, sino del signo de una nueva y total puridad, una que hace de lo híbrido su condición previa y opuesto constitutivo (Lund, 2006, p. 112; traducción propia).

Como la raza cósmica de Vasconcelos, en González, la del Gran Mulato aparece como una raza de razas: «se fundirán todos los organismos y aparecerá el verdadero hombre, EL GRAN MULATO ADAPTADO. Se fundirán todas las religiones y aparecerá una gran unidad ideológica, unidad de amor y de conciencia»(2015a, p. 68). Es una visión del mestizaje, en conclusión, que no admite la coexistencia de razas y culturas varias. Antes

17. Véase Gonźalez (2016, p. 25). 
bien, postula una evolución progresiva hacia la conformación de una sola raza que eventualmente tendría que contener a la humanidad en su conjunto.

El derrotero hacia esa utopía racial involucraba una intervención biopolítica y eugenésica en la composición racial de la población, sin la cual, pensaba González, la posibilidad de unificación humana universal en el continente amenazaba con frustrarse. A los gobiernos latinoamericanos correspondía, en primer lugar, implementar medidas higienistas y sanitarias básicas que apuntaran a la eliminación de las «endemias tropicales», la sífilis y a la lucha antialcohólica, entre otras, para así asegurar el bienestar del cuerpo social. Pero principalmente, proponía el antioqueño, los gobiernos del continente debían crear «institutos biológicos», que determinaran las regulaciones y medidas necesarias para dirigir científicamente la mezcla racial. Si de González hubiese dependido, entre las medidas encaminadas a tal fin seguramente se habría incluido, por ejemplo, la prohibición de reproducirse a ciegos, leprosos, locos, deformes y otros que pudiesen tener prole «degenerada». Sea como fuere, la tarea más importante de estos institutos, en su opinión, debía ser la de regular — restringir, de hecho— la inmigración ${ }^{18}$.

La propuesta eugenésica de González a este respecto es peculiar en su contenido específico — si bien no en sus premisas_- en comparación con las de los contemporáneos suyos, que coincidían en una explicación biológica y determinista del atraso de las sociedades latinoamericanas. Estas, como se ha señalado, recurrían a la idea de una «transfusión de sangres» como estrategia biopolítica para extinguir paulatinamente, o al menos minimizar al máximo, los componentes negro e indígena de la nación, reemplazándolos con pobladores —en la mayoría de las propuestas - europeos. Sin embargo, González se aparta notablemente de este consenso. Paradójicamente, si cabe decir, considerando su vocación universalizadora, la propuesta de González se basa en una oposición radical a la inmigración, tanto europea como asiática. La cuestión, conforme a su diagnóstico, no estaba en «mejorar» la sangre colombiana depurándola de elementos «inferiores», «bárbaros», «primitivos»—aunque esto también requiere matices que ya se harán evidentes-. Los elementos humanos requeridos para formar la raza humana

18. Véase González (2016, p. 39; 2015, pp. 33-35, 68 y 83-84). 
definitiva ya estaban aquí. Antes bien, pensaba González, la inmigración echaría a perder la posibilidad de una cultura «propia» y «original». Tal había sido el caso de Argentina y Estados Unidos, argumentaba, en los cuales toda esperanza de una contribución novedosa a la cultura universal se había frustrado por la abrumadora inmigración europea, una posición ciertamente inusual entre los intelectuales y políticos de la época.

La prédica contra la inmigración aparece en la obra de González con El hermafrodita dormido. En sus libros anteriores González no la rechazó y de hecho afirmó que es necesaria $^{19}$. Su cambio de perspectiva, sin duda, tuvo que ver con su experiencia europea mientras fue cónsul de Colombia en Italia y Francia. En dicho libro, escrito durante su estadía allí, González dio testimonio de la difícil situación que se vivía entonces en Europa con el auge de los totalitarismos y las fricciones guerreristas que ya se percibían, y aseveró que la causa principal de sus males era la superabundancia de población, razón por la cual los europeos necesitaban de las tierras americanas para obtener de ellas los recursos necesarios con el fin de sustentarla, así como para descargarse del exceso $^{20}$. En adelante mantuvo de forma consistente esa postura y sumó a su alarma la que veía como la amenaza asiática.

Un elemento clave del pensamiento racial de González, frecuentemente resaltado por sus comentaristas, es su revalorización del elemento indígena en la mezcla del continente. La Argentina, decía, carecía de originalidad cultural, puesto que justamente había perdido su «alma aborigen», situación que contrastaba con la de los países de la Gran Colombia, particularmente el Ecuador. Por eso era preciso, sostuvo, «cuidar amorosamente el tesoro aborigen» (González, 2016, p. 39). Esto, como había argumentado ya en Mi compadre, era necesario para que el nuevo tipo de humano tuviera capacidad de adaptación al medio geográfico, ya que a diferencia del negro y del blanco, el indio no era extranjero en esta tierra, una idea que deja ver el darwinismo social que impregna la teoría de González: «Sólo la sangre india es suramericana y ella dará consistencia al tipo futuro de nuestro continente, a quien yo llamo el gran mulato» (1970, p. 135).

19. González (2015a, p. 68; 1932, p. 128).

20. González (2016, p. 37). 
La mayor prueba de esa reivindicación indigenista que ven muchos de sus intérpretes estaría en las proporciones que González atribuía a cada componente para la formación de la nueva raza: «El producto verdadero de Suramérica será $45 \%$ indio; $45 \%$ blanco y $10 \%$ negro» (1970, p. 70). Respecto al negro, añadía González inmediatamente —casi disculpándose - : «Esto último lo necesitamos para la capacidad de impertinencia» (1970, p. 70). Fuera de perezoso, el negro en la obra de González es caracterizado como desfachatado, y siendo la cualidad más prominente de los suramericanos, sumado a su vergüenza y, por tanto, su tendencia a la simulación, una «pinta negra» era imprescindible para que apareciera la originalidad continental (1970, p. 15). Por su parte, al igual que el negro, el blanco tampoco provenía del trópico, y era jactancioso. Pero tenía también «imaginación creadora» (1970, p. 135). No es difícil notar los estereotipos racistas que González compartía con sus contemporáneos —y también con muchos de los nuestros-. En resumen, el «Gran Mulato» tendría la aptitud biológica para vivir en el medio tropical del indígena, la desvergüenza del negro y la superioridad racional del blanco.

Por otra parte, los tres países de la Gran Colombia, entre todos los de América, eran el escenario más propicio para la mezcla. En primer lugar, por su ubicación tropical, puesto que, afirmaba González, las cantidades de sangre requeridas para inyectar las dichas cualidades en el nuevo y definitivo tipo humano estaban ya en ellos ${ }^{21}$. El Ecuador tenía la reserva necesaria de sangre indígena. Era el más «puro» de los tres países. Pero sus indígenas estaban sumidos en sueño letárgico, oprimidos por una pequeña casta criolla europeizante $^{22}$. Venezuela, por su parte, tenía la ventaja de que en ella los tres componentes se habían mezclado completamente ${ }^{23}$. Por esa razón representaba la mayor promesa biológica de los tres países ${ }^{24} \mathrm{y}$, de hecho, afirmó González, había tenido hasta entonces los gobiernos más «auténticos», como el de su compadre Juan Vicente Gómez. Pero su pueblo era belicoso y estaba mermado a causa de la guerra de independencia y subsiguientes

21. Véase González (1970, p. 41).

22. Véase González (2016, p. 27).

23. Véase González (1970, p. 37).

24. «No quiero decir que sea más rica, que esté mejor gobernada, más organizada, etc. Hablo desde el punto de vista biológico. Ella produce hombres originales, gobiernos originales, modos propios» (González, 2016, p. 24). 
guerras civiles $^{25}$. Colombia, por último, se destacaba por su vanidad, justamente por su enorme variedad de sangres. «Cada departamento entre nosotros es un país» (2016, p. 30), se lamentaba González. Lo que había que hacer no era importar pobladores, sino favorecer el intercambio de habitantes entre los tres países, para sacar al indígena ecuatoriano de su somnolencia, vivificar y pacificar al pueblo venezolano, y homogeneizar la variopinta nación colombiana ${ }^{26}$.

En Los negroides y en otros libros, González proponía unir a los cuatro países bolivarianos. Hacer de ellos una sola nación, advertía, no era viable en el corto plazo, pero había que irlos federando poco a poco, para lo cual proponía fundar colonias para el intercambio de habitantes, construir una infraestructura de interconexión idónea, crear una representación diplomática única, otorgar el derecho de nacionalidad para los habitantes de los países de la futura federación en todos los demás y fundar una universidad grancolombiana $^{27}$. No se mostraba, en todo caso, optimista respecto a su proyecto, pues consideraba que los europeos y los asiáticos terminarían por hacerse con estos territorios y que la aparición del «Gran Mulato» se malograría.

$\mathrm{Su}$ esperanza última la fijaba en el pueblo antioqueño —un último aspecto de su propuesta de hibridación a la que vale la pena hacer mención-, pues este mostraba signos de unidad racial, en opinión de González, como ningún otro grupo humano en Suramérica. Antioquia, como una región poblada por «judíos y vascos, mezclados bastante con el negro y con el indio» (2016, p. 45), tenía la misión de unificar a la población de la Gran Colombia, como ya habría hecho en buena medida con el occidente colombiano, misión a la que el gobierno debía dedicar cuantos esfuerzos fuera preciso. De hecho, decía el envigadeño, un grave problema que tenía el país es que estaba dividido en dos por el río Magdalena, lo que había impedido que el pueblo antioqueño colonizara también el oriente de la geografía nacional. Al cumplimiento de semejante misión histórica de su pueblo se consagró González mediante sus escritos, según señaló en su revista Antioquia, ${ }^{28}$ mediante

\footnotetext{
25. Véase González (2016, pp. 45-46).

26. Véase González (2016, pp. 81-82).

27. Véase González (2016. p. 81).

28. Véase González (2013, p. 471).
} 
el lema de cuyos primeros ocho números rezaba: «El único límite de nuestro amor es Antioquia. Nuestro fin: antioqueñizar la Gran Colombia».

\section{Conclusiones}

Para concluir, es necesario referirse a un tema más que se cruza con la cuestión racial en la obra de González. Otro de los debates intensos entre la intelectualidad colombiana durante las décadas del 30 y el 40 concernía a la democracia. Entre sectores radicales de la derecha conservadora, como los Leopardos, se generó una crítica a los preceptos constitutivos de la democracia liberal (sufragio, división de poderes, etc.) y no poco entusiasmo frente a los regímenes totalitarios de Franco, Mussolini y Hitler, así como ante las perspectivas del nuevo orden mundial que estos podían imponer. González también desplegó una crítica afín y, aunque conforme se acercaba la Segunda Guerra, fue perdiendo la admiración que en varios de sus textos mostró por los líderes del fascismo europeo, coincidía con aquellos sectores en que la democracia colombiana era un puro simulacro de formas:

[...] hasta hoy hemos tenido gobiernos democráticos, según la escritura, temerosos de las leyes escritas por círculos dominantes. Democracia de escrituras. La verdadera, la de Simón Bolívar [...] consiste en gobierno que tenga raíces en el pueblo, no porque sea elegido por votos de aldeanos conducidos a las mesas de votación como rebaños, sino porque encarna las tendencias raciales y para ellas gobierna. La democracia practicada hasta hoy es formal; consiste en un método erróneo, en una creencia errónea: que por medio de papeletas, en que siempre interviene el fraude, el engaño y las pasiones más ciegas, se manifiesta la voluntad de un pueblo. Generalmente el vulgo confunde la democracia con el método desgraciado ideado para practicarla. Democracia es la encarnación de los complejos raciales en el gobernante, de tal modo que éste sea guía de la cultura, partero de la personalidad de un país (2016, p. 49; énfasis agregados).

No es algo fácil de dilucidar aquello de que la democracia es el sistema que «encarna las tendencias raciales del pueblo». González no se extendió mucho en la idea ni en la anterior referencia ni en otros contextos donde aparece. En Nociones de izquierdismo, explicó que la democracia es no solo una configuración determinada del Estado, sino una forma de organización de la sociedad que, en su conjunto, mana de la naturaleza racial del 
pueblo (2015, pp. 32-33). Sea como fuere, el punto a resaltar es que el pueblo cuyos «complejos» $\mathrm{y}$ «tendencias» raciales deben manifestarse en la organización social - $\mathrm{y}$ en el gobernante - aparece aquí, nuevamente, como una unidad indivisible y homogénea. La suya no es una propuesta de democracia racial en el sentido de un régimen político en el que las distintas razas participan equitativamente dentro de la comunidad política. Es decir, no se trata de un régimen «pluriétnico»y «multicultural». No es una democracia «entre razas», sino una democracia de «la raza» (en singular). Cabe decir entonces: no una democracia racial, sino una democracia racializada, una etnocracia, o para el caso, una «mulatocracia».

González usa este concepto en El triunfo liberal. Ensayo de sociología colombiana, escrito con el que abre el primer número de su Revista Antioquia (1936). Allí, hizo una interpretación racial de la vida republicana colombiana desde sus inicios hasta lo que había corrido de la República Liberal. Luego de la Independencia, afirmó que en Colombia se había subsistido un gobierno colonial caracterizado por un sistema segmentado de castas demarcadas según líneas raciales y que se habría ido debilitando progresivamente por causa del mestizaje, hasta que finalmente, con el ascenso del liberalismo al poder, el «hombre mezclado» se impuso sobre el blanco: «El triunfo liberal de 1931 fue étnico; la raza mulata se libertó de los criollos» (2013, p. 36). Ese acontecimiento marcaba entonces el comienzo de la «mulatocracia». Los años posteriores al cambio de régimen son retratados por González como un periodo de turbulencia social y podredumbre moral. Y es interesante notar que en su descripción no asoman por ningún lado factores políticos, ideológicos o socioeconómicos. Todo queda reducido a un conflicto racial y, de nuevo, a la condición híbrida de la población.

En dicho ensayo, la estabilidad y la viabilidad social y política de la nación, al igual que su progreso cultural, son reducidas a una cuestión de falta de unidad racial ${ }^{29}$. El problema que en última instancia planteó González, nuevamente, es qué hacer con las diferencias étnicas y raciales de la población y, más aún, cómo esa heterogeneidad puede contribuir al desarrollo y consolidación de la democracia — una cuestión que, por lo demás, continúa

29. Véase González, (2013, pp. 42-45). 
hoy irresuelta, si bien bajo nuevas formas-. En su narrativa, González propuso dos escenarios: o el Estado logra homogeneizar la población o la nación no podrá más que perecer: «Colombia será íntegramente mulata en estos cincuenta años, o colonia» (2013, p. 37). Para que la democracia funcionara, en suma, la comunidad política debía ser coextensiva con la comunidad racial, es decir, una comunidad política racializada.

¿Qué relevancia tiene, entonces, revisitar hoy la propuesta biopolítica de mestizaje eugenésico de González y su concepción mulatocrática? Ellas nos permiten apreciar varios de los presupuestos y contradicciones que atraviesan la ideología racista y eurocéntrica que compartían, con sus respectivos matices, no pocos intelectuales colombianos y latinoamericanos de su época, tras su cacareada celebración del mestizaje: particularmente, como se demostró, la idea de que hay grupos humanos híbridos y otros — hacia lo cual tenderían los primeros - racialmente formados. Al reparar en ella salta a la vista el núcleo racista de la ideología del mestizaje puesta en circulación por el ensayo latinoamericano del siglo XX, la cual involucra no solo la idea de una mezcla de «elementos puros», sino un ideal de homogeneización. De ahí que se pueda constatar, con Solodkow, que la ideología del mestizaje «ha servido como una metáfora histórica para la articulación de la Nación con sus otros, como una forma de incluir la diferencia para disiparla, borrarla, hacerla "una" o un todo» (2020, p. 38). Todo esto se puede apreciar con particular nitidez en la obra de González, debido, justamente, a su propósito de desmantelar los que veía como los presupuestos articuladores de la matriz racial eurocéntrica. Por decirlo de alguna manera, González cambió el sentido de la respuesta, pero no cuestionó los términos mismos en que se planteaba la pregunta. González no llegó (a lo mejor no podía llegar) a impugnar la categoría misma de raza, sin lo cual su proyecto crítico estaba abocado a fracasar. De ahí que en su intento de invertir la explicación determinista que relegaba a una inescapable condición de inferioridad y atraso a las sociedades latinoamericanas terminara en todo caso reproduciendo una narrativa teleológica, binaria y excluyente, en la que las diferencias étnicas y raciales de la población son revalorizadas solo por su potencial combinatorio, es decir, como elementos para la conformación de una futura comunidad política totalizada. En un elocuente corto circuito autorreferencial, su ideario biopolítico muestra el complejo de ilegitimidad, el elitismo, la paranoia racista y la ansiedad ante la heterogeneidad de las 
sociedades latinoamericanas contra los que él mismo preconizaba. Cabe recordar que al decir esto no se busca emitir un fácil juicio condenatorio, sino simplemente evitar las mistificaciones y relevar la necesidad de atender a las condiciones, complejidades y constreñimientos intelectuales e históricos que explican el desarrollo de su pensamiento y que lo condujeron, en última instancia, a desplegar una narrativa racial estrictamente eurocéntrica: el eurocentrismo puesto de cabeza, en efecto, sigue siendo eurocentrismo. Es esta una interesante paradoja que evidencia, una vez más, la enorme dificultad que implica interrogar las certezas ideológicas del tiempo en el que se vive, la tenacidad con la que estas se resisten a ser siquiera advertidas, algo que hoy puede parecer nada más que un truismo, pero de lo cual, tal vez por esa misma razón, nunca se tendrán demasiados recordatorios. Se puede echar mano de una imagen que usó Wittgenstein —en un contexto por supuesto muy distinto, pero que permite reflexionar sobre cómo la ideología no es una distorsión de la realidad, sino que la constituye-: hay ideas que están fijas en la imagen personal del mundo y de las que no se puede salir, pues no hay afuera, como lo diría el mismo Wittgenstein: «afuera falta el aire para vivir» $(2017, \S 103)$.

\section{Referencias bibliográficas}

1. Aguirre, A. (2013). Vivir a la enemiga. En Fernando González (aut.), Revista Antioquia (pp. 19-30). Medellín: Fondo Editorial EIA.

2. Aponte, L. A. (2010). Identidad colombiana en Fernando González Ochoa. Franciscanum, 52(154), 167-196.

3. Arias, R. (2011). Historia de Colombia contemporánea (1920-2010). Bogotá: Ediciones Uniandes.

4. Buitrago, J. A. (2015). La utopía racial de Fernando González Ochoa (tesis inédita de maestría). Pontificia Universidad Javeriana, Bogotá, Colombia.

5. Castro-Gómez, S. (2007). ¿Disciplinar o poblar? La intelectualidad colombiana frente a la biopolítica (1904-1934). Nómadas, 26, 44-55.

6. Díaz, D. (2008). Raza, pueblo y pobres: las tres estrategias biopolíticas en Colombia (1873-1962). En Santiago Castro-Gómez y Eduardo Restrepo (Eds.), Genealogías de la 
colombianidad: formaciones discursivas y tecnologías de gobierno en los siglos XIX y XX Bogotá: Editorial Pontificia Universidad Javeriana.

7. Escobar, M. (1997). Crónica a manera de prólogo. En Fernando González (aut.), Arengas políticas. Medellín: Universidad Pontificia Bolivariana.

8. Foucault, M. (2000). Defender la sociedad. México: Siglo XXI Editores.

9. Giraldo, E. (2012). Negroides, simuladores, melancólicos. El ser nacional en el ensayo literario colombiano del siglo XX. Medellín: EAFIT.

10. Giraldo Ramírez, J. (2016). Fernando González, metapolítico. En J. Giraldo Ramírez y

E. Giraldo (Eds.), Fernando González. Política, Ensayo y Ficción. Medellín: EAFIT.

11. Gómez, Laureano. (1970). Interrogantes sobre el progreso de Colombia. Bogotá D.C.: Editorial Revista Colombiana Ltda.

12. González, F. (1932). Don Mirócletes. París: Le Livre Libre.

13. González, F. (1933). El hermafrodita dormido. Barcelona: Juventud S.A.

14. González, F. (2016). Los negroides (Ensayo sobre la Gran Colombia). Medellín: EAFIT.

15. González, F. (1970). Mi compadre. Medellín: Editorial Bedout.

16. González, F. (2015a). Mi Simón Bolívar. Medellín: Ediciones Otraparte.

17. González, F. (2015). Nociones de izquierdismo. Medellín: EAFIT.

18. González, F. (2013). Revista Antioquia (1936-1945). Medellín: Fondo Editorial EIAEscuela de Ingeniería de Antioquia.

19. Henao, J. (1988). Fernando González, filósofo de la autenticidad. Medellín: Editorial Universidad.

20. Jiménez, D. (2009). Revolución: imágenes, ideas, relatos. En R. Sierra Mejía (Ed.), República Liberal: cultura y sociedad. Bogotá: Universidad Nacional de Colombia, Facultad de Ciencias Humanas.

21. López de Mesa, L. (1970). De cómo se ha formado la nación colombiana. Medellín: Editorial Bedout.

22. Marquínez, G. (2007). Fernando González Ochoa (1985-1964). En Santiago CastroGómez et al. (Eds.), Pensamiento colombiano del siglo XX. Bogotá: Pontificia Universidad Javeriana. 
23. Murcia, D. (2016). El devenir de los caudillos en el devenir del Gran Mulato (Sobre mi compadre). En J. Giraldo Ramírez \& E. Giraldo (Eds.), Fernando González. Política, Ensayo y Ficción. Medellín: EAFIT.

24. Pachón, D. (2915). El pensamiento político de Fernando González Ochoa: del rastacuersimo a la autoexpresión del individuo. Ciencia Política, 10(20), 151-75.

25. Pedraza, Z. (1997). El debate eugenésico: una visión de la modernidad en Colombia. Revista de Antropología y Arqueología, 9(1-2), 115-159.

26. Quijano, A. (2000). Colonialidad del poder, eurocentrismo y América Latina. En E. Lander (Comp.), La colonialidad del saber: eurocentrismo y ciencias sociales. Perspectivas latinoamericanas. Buenos Aires: CLACSO.

27. Pinto, G. (1995). Fernando González y nosotros. Medellín: Concejo de Medellín.

28. Rivera, A. (2016). La filosofía política de Fernando González: la lucha por la personalidad del pueblo suramericano. En J. Giraldo Ramírez y E. Giraldo (Eds.), Fernando González. Política, Ensayo y Ficción. Medellín: EAFIT.

29. Solodkow, D. (2020). Mestizaje inconcluso, raza y gobierno de la población. Luis López de Mesa y el ensayo biopolítico en Colombia. Universidad de los Andes, Bogotá.

30. Vasconcelos, José. (1966). La raza cósmica. México: Austral.

31. Virno, P. (2013). An Equivocal Concept: Biopolitics. En T. Campbell \& A. Sitze (Eds.), Biopolitics: A Reader (pp. 269-273). Durham: Duke University Press.

32. Wittgenstein, L. (2017). Investigaciones filosóficas. Madrid: Trotta. 